\title{
Alumina/Zirconia Micro/Nanocomposites: A New Material for Biomedical Applications With Superior Sliding Wear Resistance
}

\author{
José F. Bartolomé ${ }^{\dagger}$ \\ Instituto de Ciencia de Materiales de Madrid, Consejo Superior de Investigaciones Científicas (CSIC), \\ Madrid 28049, Spain
}

Antonio H. De Aza

Instituto de Cerámica y Vidrio , Consejo Superior de Investigaciones Científicas (CSIC), Madrid 28049, Spain

Antonia Martín, José Y. Pastor, and Javier Llorca*

Departamento de Ciencia de Materiales, Universidad Politécnica de Madrid \& Instituto Madrileño de Estudios Avanzados en Materiales (IMDEA-Materiales), E.T.S. de Ingenieros de Caminos, Madrid 28040, Spain

Ramón Torrecillas

Instituto Nacional del Carbón, Consejo Superior de Investigaciones Científicas (CSIC), Oviedo 33011, Spain

Giovanni Bruno $\ddagger$

Materials Science Centre, University of Manchester, Manchester M1 7HS, U.K.

In the present investigation, the sliding wear behavior is described for $\mathrm{Al}_{2} \mathrm{O}_{3} / \mathrm{ZrO}_{2}$ micro/nanocomposites and monolithic alumina of similar grain size under defined conditions of a constant sliding speed and different loads (20-150 N). Nano $\mathrm{ZrO}_{2}$ particles $(1.7 \mathrm{vol} \%)$ were observed uniformly distributing throughout the composites, and most of them were located within the matrix alumina grains. The wear rate of the alumina and the micro/nanocomposites increased as the contact load increased and a clear transition in friction and wear behavior was observed in both materials. However, the nanocomposite wear resistance at low contact loads was one order of magnitude higher than that of the alumina. In the severe regime, no difference was observed among the materials. The low wear rate $\left(10^{-7} \mathrm{~mm}^{3} \cdot(\mathrm{N} \cdot \mathrm{m})^{-1}\right)$ along with low pullout indicates higher wear resistance of micro/nanocomposites in the mild regime compared with monolithic alumina. Based on the morphological observation of worn surfaces by scanning electron microscope and on residual stress analysis performed by neutron diffraction, some wear mechanisms of $\mathrm{Al}_{2} \mathrm{O}_{3}-\mathrm{ZrO}_{2}$ micro/nanocomposites are proposed. The high wear resistance of the nanocomposites is discussed in terms of fracture resistance properties and residual stress. Improvements in mechanical and tribological properties of these composites make them promising candidates for biomedical applications.

M. Rigaud - contributing editor

Manuscript No. 22867. Received March 2, 2007; approved June 2, 2007.

This work was supported by EU under project reference FP6-515784-2, by the Spanish Ministry of Science and Technology under project number MAT2006-10249-C02-01 and by the "Dirección General de Universidades e Investigación de la Consejería de Educación y Ciencia de la Comunidad de Madrid" and CSIC under project reference 200660M042. J. F B. has been supported by Ministry of Science and Technology and CSIC under the "Ramón y Cajal" Program cofinanced by European Social Fund. Beam time was granted by ILL, Exp. No. 7-01-163.

${ }^{*}$ Member, American Ceramic Society.

${ }^{\dagger}$ Author to whom correspondence should be addressed. e-mail: jbartolo@icmm.csic.es

${ }^{\ddagger}$ Present address: Corning SAS, CETC, F-77210, Avon, France.

\section{Introduction}

T $\mathrm{T}$ has been demonstrated that the sliding wear resistance of alumina can be considerably improved by zirconia additions. ${ }^{1-5}$ One possible explanation for this remarkable improvement is the prevention of grain growth. In most cases, a finer grain size of alumina leads to lower specific wear rates. Previous works ${ }^{4,6-8}$ have demonstrated that the grain size effect can be predicted by considering the combined effects of the contact stresses and the preexisting thermal mismatch stresses (generated as a result of the anisotropy of the thermal expansion coefficient of alumina) and a time-dependent damage accumulation mechanism. In the initial stage of wear, the generation and gradual accumulation of dislocations and twins leads to internal stresses sufficient to initiate subsequent fracture. ${ }^{9-11}$ The grain size effect results from both the scaling of thermal mismatch stresses with grain size, but also the increase of the slip length and therefore dislocation density with grain size. Additionally, due to plastic anisotropy, the configuration and density of intersecting dislocation arrays and twins depend upon the grain orientation.

On the other hand, the use of metastable zirconia particles as a reinforcing element improves the wear resistance through the suppression of crack initiation and propagation due to the higher value of the fracture toughness. The transformed particles in the near-surface area induce a compressive stress field, which serves as a toughening mechanism: it reduces the crack-driving force for any existing surface or subsurface cracks. However, the very same particles also introduce surface uplift due to the accompanying dilatation and shear. The uplift alters the surface topography and thereby the sliding conditions. Recently, Bartolome et al. ${ }^{12}$ found that the wear rate, at relatively low normal loads $(20 \mathrm{~N})$, of $\mathrm{Al}_{2} \mathrm{O}_{3}$ reinforced with $22 \mathrm{vol} \%$ yttria-stabilized zirconia (3Y-TZP) is around two orders of magnitude higher than the ones corresponding to 14 and $7 \mathrm{vol} \% 3 \mathrm{Y}$-TZP content. This result has been explained in terms of the infinite cluster formed at the percolation threshold. Above the critical 3Y-TZP fraction of $\approx 16 \mathrm{vol} \%$, corresponding to the percolation threshold, a continuous path between zirconia particles sets in. In these particular cases, wear is dominated by a percolative mechanism so that the $t \rightarrow m$ zirconia transformation creates a microcrack 
network, which controls the wear resistance of the composite. Additionally, the transformable particles in zirconia-toughening alumina (ZTA) composites are usually nonuniformly distributed and therefore result in an uneven surface uplift. The presence of relatively large monoclinic zirconia particles at grain boundaries creates sufficient stresses to cause microcracking at the aluminazirconia interfaces, that in some cases, extends along the alumina-alumina grain boundaries. These grains of zirconia and alumina, isolated as they are from the matrix by microcraking, are then vulnerable to removal by the abrasive. ${ }^{13}$ Therefore, there is a need to alter the microstructure in such a way as to provide the maximum possible crack tip shielding without exceeding a tolerable surface uplift. In order to find such a compromise solution, a fine grain size and refined microstructure are necessary.

Traditional methods for obtaining ZTA composites by mixing and milling have been commonly applied, but tend not to yield ideal phase distributions. The materials show a poor microstructural homogeneity, particularly with respect to grain size and dispersion of the $\mathrm{ZrO}_{2}$ phase. Recently, innovative processing routes have been used to obtain very fine microstructures with a narrow distribution of zirconia particles homogeneously dispersed in the alumina matrix at grain boundaries. ${ }^{\text {14-19 }}$ This leads to a high portion of tetragonal phase retained after sintering with the ability to transform under applied stress. ${ }^{20}$ Thomsen and Karihaloo ${ }^{21}$ have calculated, using a mathematical optimization procedure, that the volume fraction of the transformable phase in the near-surface region for transformation-toughened ceramics should be in the range from $3 \%$ to $10 \%$ in order to avoid excessive surface uplift. However, there always exists a possible uneven distribution of transformed particles throughout the material. In some applications, like the femoral head implants, the increase of the surface implant roughness and microcraking due to a transformation of specific agglomerated zirconia grains can have a dramatic effect on their life span. ${ }^{22}$ Therefore, the presence of zirconia aggregates, especially if the zirconia is stabilized with yttria, should be avoided. ${ }^{23}$

Experiments carried out by many researchers ${ }^{24,25}$ have shown that the mechanical properties and wear of alumina can be significantly enhanced by the dispersion of ceramic particles in the nanometer size range. The reinforcement was found to be significantly higher than that achieved with a microcomposite, particularly when using a low content of nanoparticles $(<10 \mathrm{vol} \%)$. Several mechanisms have been proposed for the enhancement of the mechanical properties (strength and toughness) of nanocomposites; these include thermal residual stresses, change in grain boundary morphology, dislocation activity, enhanced interfacial fracture energy, etc. ${ }^{26}$ However, the most remarkable and reliable benefit offered by nanocomposites is in their tribological properties. In recent works, for $\mathrm{Al}_{2} \mathrm{O}_{3}-\mathrm{SiC}$ nanocomposites, considerable improvements in the resistance to severe wear and surface finish following grinding and polishing have been reported $^{27-31}$ compared with pure alumina. These nanocomposites tend to exhibit a surface covered in plastic deformation grooves, while for the same severe wear conditions, the monolithic exhibits an intergranular fracture. Therefore, the transition from mild to severe wear, which is commonly observed in alumina after a sliding wear critical time, is suppressed in the $\mathrm{Al}_{2} \mathrm{O}_{3}-\mathrm{SiC}$ nanocomposites. However, the wear rate of the monolithic alumina in the mild wear regime was lower than that of the nanocomposites. ${ }^{32}$ The understanding of the material-removal mechanisms in the mild regime has not received sufficient attention, despite being one of the most important factors, and consequently is the least understood area. The majority of wear studies report the worm surface structures and specific wear rates that place them firmly in the severe wear regime. ${ }^{33,14}$ Moreover, the use of ceramics in engineering applications (mechanical seals, prosthetic devices, ball bearings, etc.) requires operation in the mild wear regime.

Neutron diffraction is well suited to measure the residual strain and stress distribution because of the high penetration depth compared with laboratory X-rays (generally three orders of magnitude greater-millimeters versus micrometers). This prevents the bias in results due to surface effects, e.g., cutting, machining, etc., of the samples. Diffraction stress measurements basically consist of measuring the cell parameters, or interplanar spacing, of a material and using the changes from unstressed values to obtain strain, and then stress values. When a material is subject to a homogeneous strain field, the angular position of a diffraction peak will shift to lower or higher $2 \theta$ values, depending on whether the strain is tensile or compressive. Residual stress in each phase can be deduced from the lattice strain by using basic linear elasticity. On the other hand, if the material is subjected to an inhomogeneous strain field, then in addition to a possible shift in the peak position, the diffraction peak profile will also be broadened. Thus, while the shift of a peak measures the average lattice strain along a particular crystallographic direction, the breadth of the peak provides useful information about the distribution or fluctuation of the inhomogeneous strain field.

Recently, a new alumina/zirconia nanostructured ceramic with only $1.7 \mathrm{vol} \%$ of nanoparticles of zirconia with an average size of $150 \mathrm{~nm}$ has been fabricated. ${ }^{34}$ These composites, due to the compressive residual stress developed, show fracture resistance properties that were never reached with oxide ceramics so far. The purpose of the present work is to analyze the influence of the distribution of residual stresses from measurements of strain by neutron diffraction on the toughening mechanism and sliding wear resistance of $\mathrm{Al}_{2} \mathrm{O}_{3}-\mathrm{ZrO}_{2}$ nanocomposites, mainly in the mild regime.

\section{Experimental Procedure}

\section{(1) Material Processing}

A modified colloidal route was conducted to synthesize the nanostructured composite powder. This processing route was described in detail elsewhere. ${ }^{18}$ It consists of doping a stable suspension of a high-purity alumina powder $\alpha-\mathrm{Al}_{2} \mathrm{O}_{3}>99.9 \mathrm{wt} \%$ (Condea HPA 0.5 , Ceralox Division, Tucson, AZ), with an average particle size of $0.45 \mu \mathrm{m}$ and a surface area of $10 \mathrm{~m}^{2} / \mathrm{g}$ (values given by the supplier), in absolute ethanol $(99.97 \%$ ) by dropwise addition of a diluted (2/3 vol\% $\mathrm{Zr}$ alkoxide, $1 / 3 \mathrm{vol} \%$ absolute ethanol) zirconium alkoxide (Aldrich zirconium IV propoxide, $70 \mathrm{wt} \%$ solution in 1-propanol, Sigma-Aldrich, Madrid, Spain). In the present work, a low amount of zirconia precursor was added, to obtain composites with only $1.7 \mathrm{vol} \%(2.5 \mathrm{wt} \%)$ zirconia nanoparticles. After drying under magnetic stirring at $70^{\circ} \mathrm{C}$, the powders were thermally treated at $850^{\circ} \mathrm{C}$ for $2 \mathrm{~h}$ in order to remove organic residues and were subsequently attrition milled with alumina balls for $1 \mathrm{~h}$. The powders were dried and sieved to $<45 \mu \mathrm{m}$. A stable aqueous suspension of $65 \mathrm{wt} \%$ solids content using $1 \mathrm{wt} \%$ addition of an alkali-free organic polyelectrolite (Dolapix C64, Zschimmer \& Schwarz, Villarreal, Spain) was ball milled using high-purity alumina balls in an alumina jar for $24 \mathrm{~h}$. Plates (100 $\mathrm{mm} \times 100 \mathrm{~mm} \times 5 \mathrm{~mm}$ ) were cast from the suspension in plaster of Paris mold and dried in air at room temperature for $48 \mathrm{~h}$. Samples were then sintered at $1600^{\circ} \mathrm{C}$ for $2 \mathrm{~h}$ in air. Sintered plates were then machined to small bars of $4 \mathrm{~mm} \times 3 \mathrm{~mm} \times 40 \mathrm{~mm}$.

\section{(2) Material Characterization}

Scanning electron micrographs were obtained using a Jeol (Tokyo, Japan) JSM 6500f with an accelerating tension of $10 \mathrm{kV}$. Polished samples were preliminarily thermally etched in an air atmosphere at $1450^{\circ} \mathrm{C}$ for $30 \mathrm{~min}$, at heating and cooling rates of $400^{\circ} \mathrm{C} / \mathrm{h}$. Samples were then gold coated before scanning electron microscope (SEM) analysis.

The grain size of the alumina matrix was determined using the linear intercept method. To determine the $\mathrm{ZrO}_{2}$ grain size distribution, micrographs were taken of representative regions and the equivalent spherical diameters of 100 grains were measured.

The Vickers hardness, $H_{\mathrm{v}}$, and fracture toughness, $K_{\mathrm{IC}}$, were measured using a Vickers diamond indenter (Leco 100-A, St. Joseph, MI) on polished surfaces, with applied loads of 9.8 and $490 \mathrm{~N}$, respectively. The corresponding indentations sizes and crack lengths were determined using an optical microscope 
(Leica DMRM, Cambridge, U.K.). The fracture toughness was calculated using the formula given by Miranzo and Moya. ${ }^{35}$

The bending strength, $\sigma_{\mathrm{f}}$, was determined by a three-point bending test on prismatic bars with $4 \mathrm{~mm}$ width, $45 \mathrm{~mm}$ length, and $3 \mathrm{~mm}$ thickness cut from the sintered pieces. The tensile surface was polished down to $1 \mu \mathrm{m}$. The tests were performed at room temperature using a universal testing machine (Instron Model 4411, Boston, MA). The specimens were loaded to failure with a cross-head speed of $0.5 \mathrm{~mm} / \mathrm{min}$ and a support span of $40 \mathrm{~mm}$. Reported strengths represented the mean and standard deviation of 20 specimens, and were calculated according to the equation

$$
\sigma_{\mathrm{f}}=\frac{3 Q L}{2 l h^{2}}
$$

where $Q$ is the failure load, $L$ is the span, $l$ is the width, and $h$ is the height.

The Young's modulus was obtained from the slopes of loaddeflection curves of three-point bending tests. A static extensometer was used to measure the deflection with an error in the measurement of $\approx 0.1 \%$.

\section{(3) Wear Test Setup and Conditions}

Wear tests were performed by rubbing a $\mathrm{MgO}$-partially stabilized $\mathrm{ZrO}_{2}(\mathrm{MgO}-\mathrm{PSZ})$ sphere $5 \mathrm{~mm}$ in diameter against the specimen surface in an oscillating friction machine (Model 77, Cameron-Plint, Wokinham, U.K.). The $\mathrm{ZrO}_{2}$ spheres were held to avoid rolling during the test. All tests were performed at room temperature with a sliding speed of $0.15 \mathrm{~m} / \mathrm{s}$ and $15 \mathrm{~mm}$ of the total amplitude of the oscillations. At least four sliding wear tests were conducted for each composition $\left(\mathrm{Al}_{2} \mathrm{O}_{3} / \mathrm{ZrO}_{2}\right.$ micro/nanocomposites and monolithic alumina). The weight loss was measured using an electronic balance (Mettler-Toledo, Greifensee, Switzerland) with a resolution of $0.01 \mathrm{mg}$, with the specimen removed periodically from the machine. Both the specimen and the sphere were cleaned in an ultrasonic acetone bath before testing and every time the test was interrupted to determine the wear loss. Normal loads of $20-150 \mathrm{~N}$ were used. The total sliding distance of the tests was changed for each specific loading condition to increase the total wear and reduce the relative error. The corresponding initial Hertzian mean contact pressures, $P$, for normal loads were calculated from

$$
P_{\text {Hertz }}=\frac{1}{3 \pi}\left(\frac{3 F E_{\mathrm{r}}^{2}}{R_{\mathrm{r}}^{2}}\right)^{\frac{1}{3}}
$$

where $F$ is the applied normal force, $E_{\mathrm{r}}$ is the reduced elastic modulus, and $R_{\mathrm{r}}$ is the reduced radious. $E_{\mathrm{r}}$ and $R_{\mathrm{r}}$ are defined by $1 / E=1 / 2\left[\left(1-v_{1}^{2}\right) / E_{1}+\left(1-v_{2}^{2}\right) / E_{2}\right]$ where $E_{1}$ and $E_{2}$ are the elastic moduli and $v_{1}$ and $v_{2}$ are Poisson's ratios of the sphere and the material, respectively. $R_{\mathrm{r}}=R / 2$ where $R$ is the radius of curvature of the sphere.

\section{(4) Neutron Diffraction}

Neutron diffraction residual stress analysis was carried out on sintered prismatic bars of $\mathrm{Al}_{2} \mathrm{O}_{3} / \mathrm{ZrO}_{2}$ micro/nanocomposites and monolithic alumina. Measurements were performed on the strain scanner (SALSA) at the Institute Laue-Langevin (ILL, Grenoble, France). ${ }^{36,37}$ The 311 reflection of the double-focusing $\mathrm{Si}$ monochromator was used at a take-off angle of $85^{\circ}$ to obtain a wavelength of $\lambda=1.77 \AA$. A $2 \mathrm{D}$ position-sensitive detector with an angular opening of approximately $5^{\circ}$ was mounted on SALSA. Primary and secondary slits defined a gauge volume of $1.5 \mathrm{~mm} \times 1.5 \mathrm{~mm} \times 10 \mathrm{~mm}$. Typical counting times with this setup varied from 5 to $30 \mathrm{~min}$ to account for the small $\mathrm{ZrO}_{2}$ content. For $\mathrm{Al}_{2} \mathrm{O}_{3}$, the 119 reflection was selected that produces a Bragg peak at $2 \theta=89^{\circ}$. For the $\mathrm{ZrO}_{2}$, the 220 peak was chosen for strain scanning, at diffraction angle $2 \theta=86^{\circ}$. These peaks were chosen because they had a relatively high in- tensity, and no overlap with other peaks. Moreover, as mentioned in Webster, ${ }^{38}$ the angular region $20 \sim 90^{\circ}$ satisfies a homogenous coverage of the gauge volume while rotating the sample. A fitting model with Gaussian peaks has been adopted. The LAMP software ${ }^{39}$ was used to analyze the experimental results and obtain the peak parameters (intensity, position, and width) at each sample orientation. The lattice elastic strain, as averaged within the gauge volume and in the direction of the scattering vector, is given by

$$
\varepsilon_{h k l}=\left(d_{h k l}-d_{h k l}^{0}\right) / d_{h k l}^{0}=-\Delta \theta \cot \theta_{0}
$$

where $d_{h k l}$ and $d_{h k l}^{0}$ are, respectively, the $h k l$ interplanar spacing of the sample and of the unstressed one (reference). For a monochromatic beam, any change in lattice spacing will cause a corresponding shift $\Delta \theta$ in the angular position of the Bragg reflection. Monolithic $\mathrm{Al}_{2} \mathrm{O}_{3}$ ceramic processed in the same way as the composites and corundum ( $\alpha$-alumina) powder (held in vanadium cans) with a similar average grain size as in the final composites were used as reference materials, because no macrostress is expected. The samples were rotated in the scattering plane and measured for two perpendicular orientations, but the average was carried out after the (expected) observation of isotropy of the in-plane strain.

Consequently, in order to calculate the stress, hydrostatic formulae were used

$$
\sigma=\frac{E}{3(1-v)} \varepsilon
$$

because, as it will be seen later, the different orientations indeed gave very similar strains.

\section{Results}

\section{(1) Microstructural Analysis and Mechanical Properties}

Figure 1 shows SEM images of a thermally etched, polished section of monolithic $\mathrm{Al}_{2} \mathrm{O}_{3}$, and the $\mathrm{Al}_{2} \mathrm{O}_{3}-\mathrm{ZrO}_{2}$ micro/nanocomposites. The $\mathrm{ZrO}_{2}$ and $\mathrm{Al}_{2} \mathrm{O}_{3}$ grains are the brighter and darker phase, respectively. The micro/nanocomposite shows zirconia nanoparticles evenly distributed in the alumina matrix. Those zirconia particles were found both in inter- and intragranular regions, the latter being the majority. Intragranular nanoparticles showed an almost perfect spherical shape with a median grain size of $\approx 150 \mathrm{~nm}$. The alumina grains $\left(D_{50} \approx 6 \mu \mathrm{m}\right)$ exhibit a relatively broad grain size distribution, and many grains are tabular or elongated. The presence of intragranular $\mathrm{ZrO}_{2}$ may be caused by this grain growth. Normally, the boundary migration can be inhibited by nanoscale particles at grain boundary during sintering. If the resistance of $\mathrm{ZrO}_{2}$ particles cannot counteract the driving force for grain boundary migration, the matrix grain boundary would jump across the secondphase particles, and admit the intragranular $\mathrm{ZrO}_{2}$ particles within alumina grains. When the grain boundary reaches a particle, the boundary energy will decrease by a value proportional to the cross-sectional area of the particle. Then, a breakaway stress will have to be applied in order to release the boundary from the pinning particle. Observations that nanoparticles with sizes of $\sim 50-300 \mathrm{~nm}$ are usually trapped within matrix grains indicate that grain boundaries are easy to break away from small particles. Their contribution to pinning can therefore be neglected, as a rough approximation.

The monolithic alumina exhibits a bimodal grain size distribution, with large, high-aspect ratio grains, surrounded by a finer more equiaxed grain size matrix. The mean particle size was $\approx 7 \mu \mathrm{m}$, very similar to the nanocomposite one. This is important in a comparative study because grain size is known to strongly affect the time to a wear transition.

Table I gives the density, Vickers hardness $\left(H_{\mathrm{v}}\right)$, Young's modulus $(E)$, flexure strength $\left(\sigma_{\mathrm{f}}\right)$, and indentation fracture toughness $\left(K_{\mathrm{I} C}\right)$ of the monolithic alumina and nanocomposite. Both fracture toughness and flexure strength increased substan- 

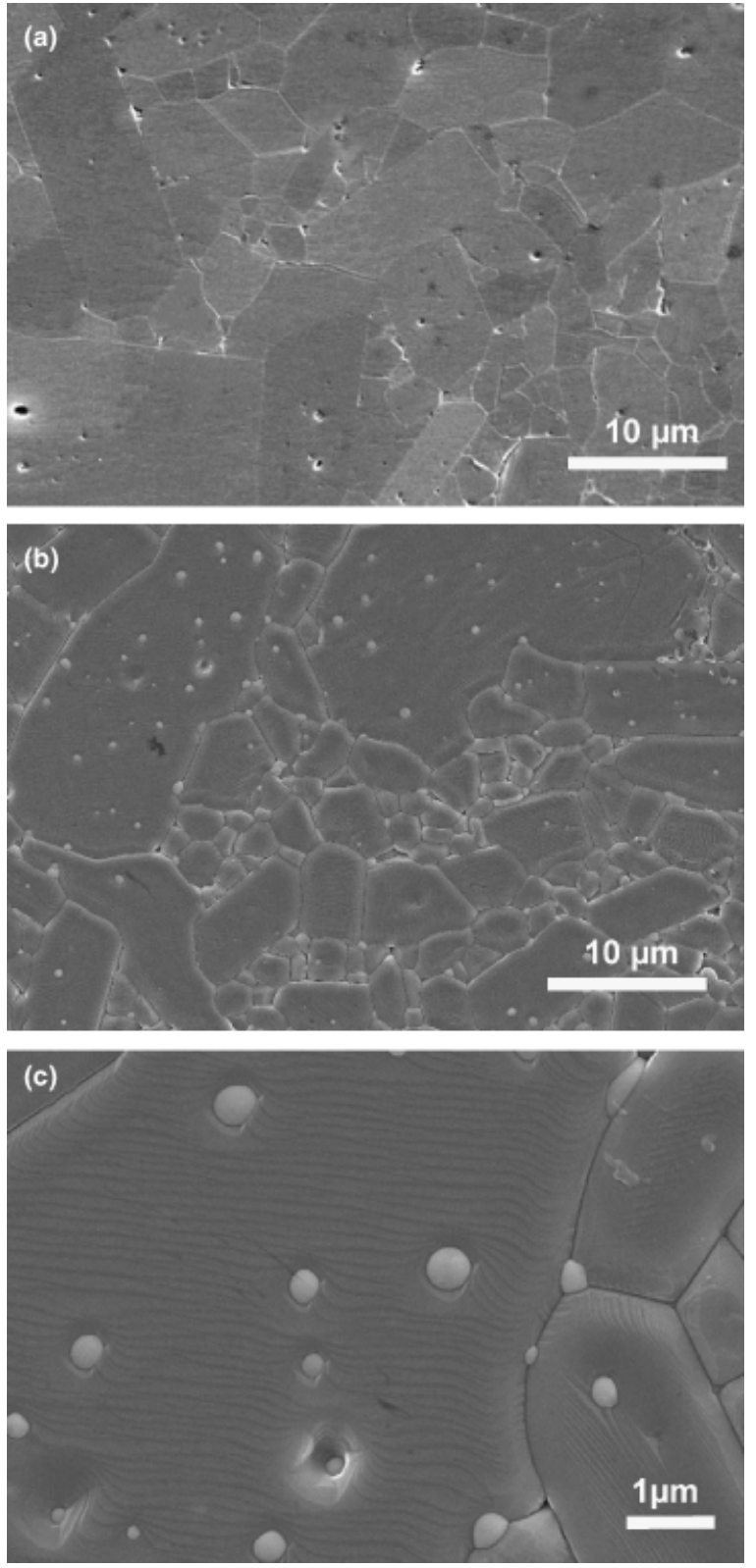

Fig. 1. Scaning electron micrograph of (a) $\mathrm{Al}_{2} \mathrm{O}_{3}$, (b) $\mathrm{Al}_{2} \mathrm{O}_{3}-\mathrm{ZrO}_{2} n$, and (c) close-up showing nanosized zirconia particles embedded in the alumina matrix, after thermal etching; matrix grains are alumina, white grains are zirconia particles.

tially with the addition of just 1.7 vol $\% \mathrm{ZrO}_{2}$ nanoparticles. Young's modulus and Vickers hardness of the $\mathrm{Al}_{2} \mathrm{O}_{3}$ matrix were not considerably affected by the presence of $\mathrm{ZrO}_{2}$ nanoinclusions.

\section{(2) Wear Test Data}

Figure 2 shows the specific wear rate as a function of load for the monolithic alumina and $\mathrm{Al}_{2} \mathrm{O}_{3}-\mathrm{ZrO}_{2}$ nanocomposite. The two

Table I. Mechanical Properties of $\mathrm{Al}_{2} \mathrm{O}_{3}$ and Micro/ Nanocomposites

\begin{tabular}{|c|c|c|c|c|}
\hline & $\begin{array}{l}\text { Stregth, } \\
\sigma_{\mathrm{f}}(\mathrm{MPa})\end{array}$ & $\begin{array}{c}\text { Young's } \\
\text { modulus, } \\
E(\mathrm{GPa})\end{array}$ & $\begin{array}{c}\text { Toughness, } K_{\mathrm{IC}} \\
\left(\mathrm{MPa} \cdot \mathrm{m}^{1 / 2}\right)\end{array}$ & $\begin{array}{l}\text { Hardness, } \\
H_{\mathrm{V}}(\mathrm{GPa})\end{array}$ \\
\hline $\mathrm{Al}_{2} \mathrm{O}_{3}$ & $335 \pm 20$ & $375 \pm 8$ & $3.2 \pm 0.2$ & $20 \pm 2$ \\
\hline $\begin{array}{l}\mathrm{Al}_{2} \mathrm{O}_{3}-\mathrm{ZrO}_{2} \text { micro/ } \\
\text { nanocomposites }\end{array}$ & $603 \pm 17$ & $360 \pm 5$ & $6.3 \pm 0.3$ & $20 \pm 2$ \\
\hline
\end{tabular}

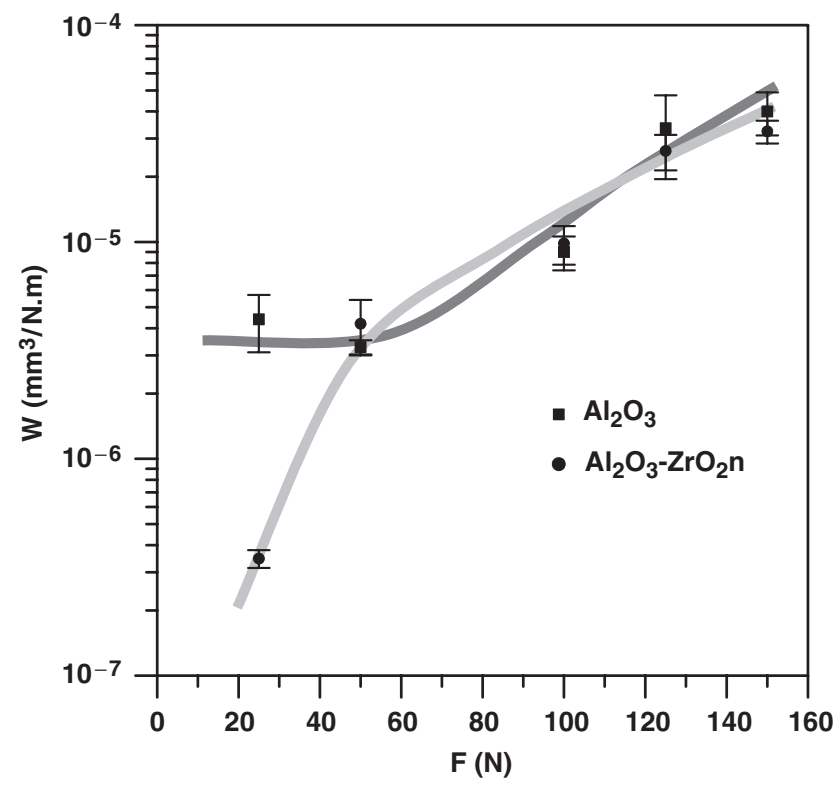

Fig. 2. Effect of normal loads on the wear rates of materials.

materials exhibit similar behavior if the load is higher than $50 \mathrm{~N}$. In contrast, the monolithic material shows an order of magnitude higher specific wear rate at $20 \mathrm{~N}$ (Hertzian contact pressure of $1.1 \mathrm{GPa}$ ). Examination of the material wear surfaces confirmed that the observed changes in wear rate behavior are related to a fundamental change in wear mechanism. Figure 3(a) shows an SEM micrograph of the worn surface of the monolithic alumina after testing at $20 \mathrm{~N}$. The surface layer is formed by isolated islands of compacted debris. The underlying surface shows evidence of grain pullout, mainly by intergranular grain fracture. Figure 3(b) shows that a nearly continuous layer of very fine debris $(<0.5 \mu \mathrm{m})$ was formed, and separated the two original surfaces. The small particle size and shape of the wear debris indicated that they were probably removed from the material by plastic deformation and microcracking, which are characteristic features of abrasive wear. Plastic deformation results from adhesion and smearing of the wear debris, which form heavily deformed smooth patches.

In contrast, the nanocomposite worn surface generated under the same slinding wear conditions was generally smooth (Fig. 4). Occasional evidence of pullout was observed.

In wear tests conduced on pure alumina, the wear rate increased after $50 \mathrm{~N}$ normal loading and revealed a cracking threshold between 50 and $100 \mathrm{~N}$. Under these severe conditions, the nanocomposite presents similar features. In Fig. 5, the general appearance of nanocomposite wear surfaces tested under a normal load of $150 \mathrm{~N}$ (Hertzian contact pressure of $2.2 \mathrm{GPa}$ ) is shown. Rough regions are observed, which are very irregular and deeply grooved. This indicates a large degree of microcracking at the contact surface and in the subsurface. Consequently, the wear mechanism is dominated by intergranular fracture and grain pullout characteristic of chipping wear. Some plastic deformation is still evident, in the form of grooves created by the abrasive process, but delamination of the wear sheet and subsurface fracture are both common features of the worn layer. The fracture process initially occurs within "patches" of grains, and then proceeds rapidly over the entire contact area. Although eventually some degree of transgranular fracture is observed, appreciable wear after prolonged sliding appears to occur primarily by continued intergranular fracture and grain pullout. Therefore, the transition from mild wear (plastic deformation controlled) to severe wear (microfracture controlled) for both materials has started at a normal load of $50 \mathrm{~N}$. In the mild wear region $(20 \mathrm{~N})$, removal of material by such different mechanisms led to different wear rates and worn surface roughness. 

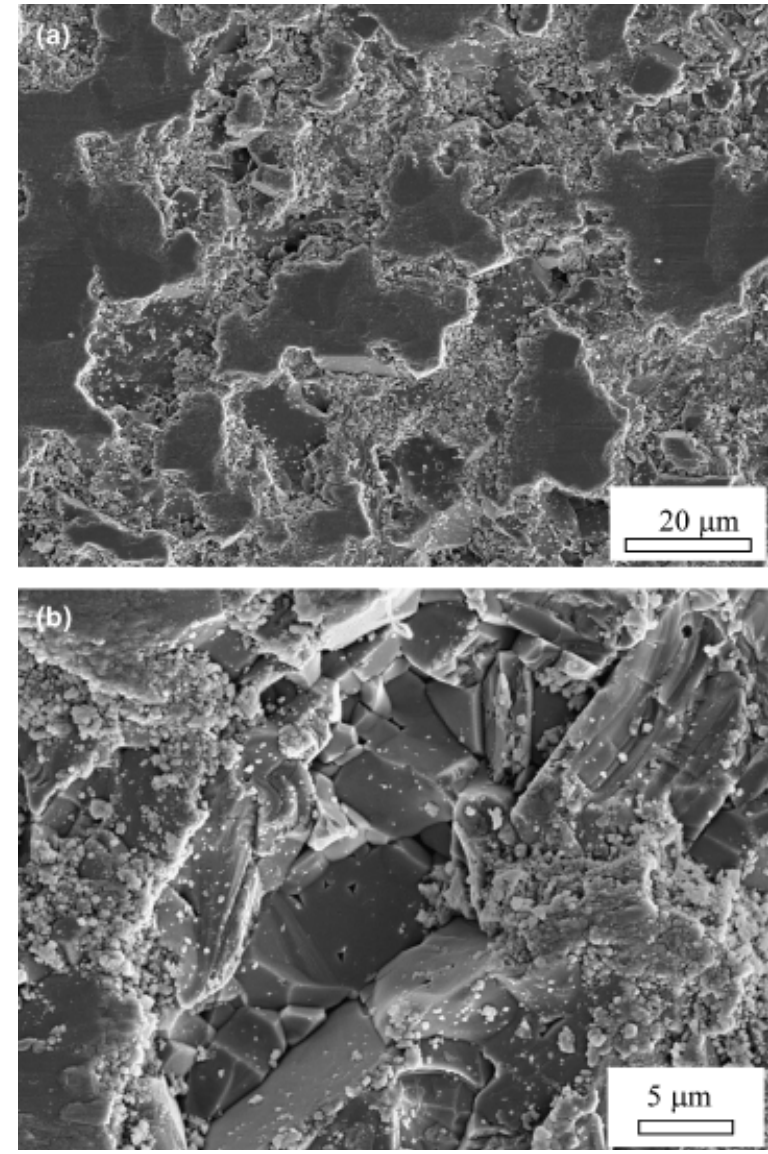

Fig. 3. Scanning electron micrograph of the worn surface of monolithic alumina (mild regime at $20 \mathrm{~N}$ ). (a) Compacted islands of debris spread over the surface. (b) Microstructure of the underlying surface showing intergranular fracture and loose debris.

\section{(3) Neutron Diffraction}

The two measured sample orientations were observed to possess basically the same strain in each sample. This confirmed the hypothesis that the stress state should be hydrostatic within the gauge volume considered. An average value of the two measurements (directions) was therefore taken. It must be noted that no peak could be detected for the $\mathrm{ZrO}_{2}$ nanoparticles. The strain in the alumina (again, averaged over the gauge volume) could be measured. The residual strains were calculated using Eq. (3), taking the $\mathrm{Al}_{2} \mathrm{O}_{3}$ bulk sample as a reference. From the strain,

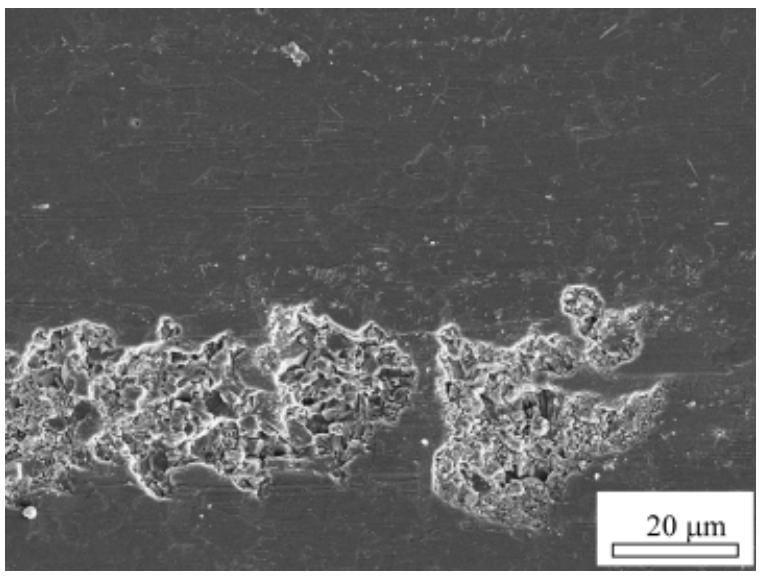

Fig. 4. Scaning electron micrograph of the worn surface of a nanocomposite after sliding against a $\mathrm{MgO}-\mathrm{PSZ}$ sphere under normal load of $20 \mathrm{~N}$.
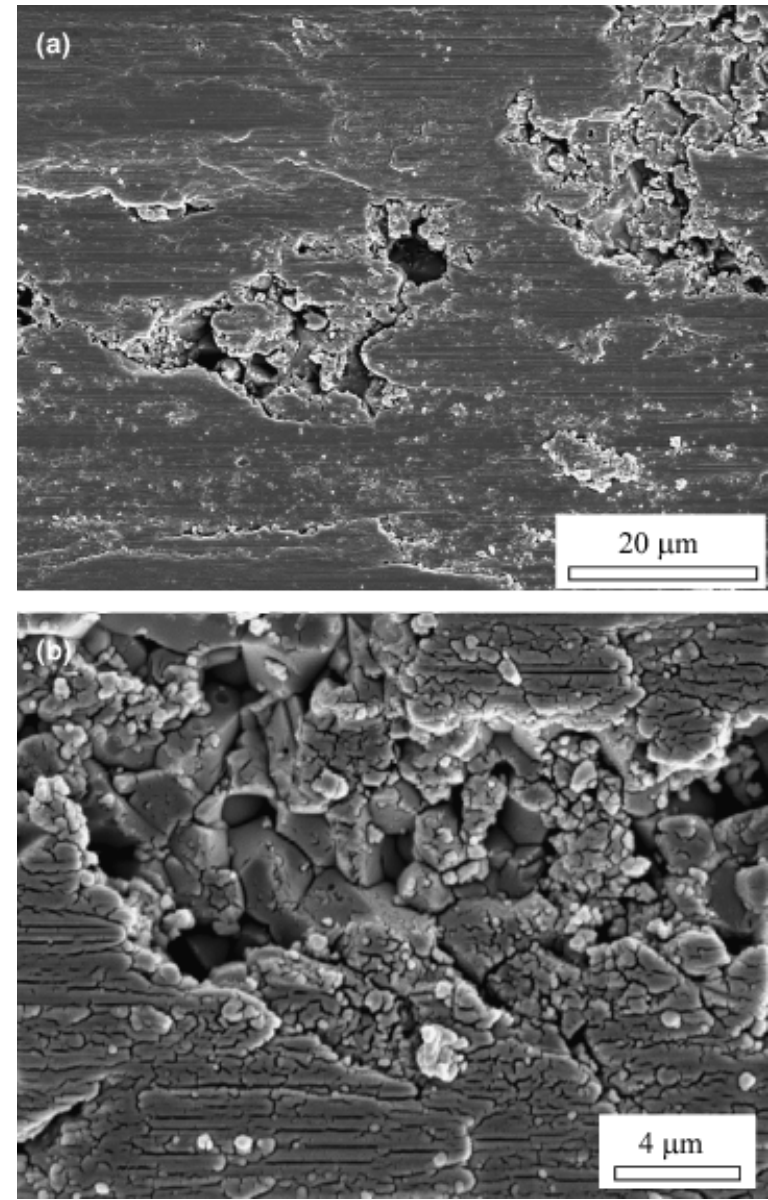

Fig. 5. Scanning electron microscopic image of the worn surface of the $\mathrm{Al}_{2} \mathrm{O}_{3}-1.7 \% \mathrm{ZrO}_{2}$ tested under a load of $150 \mathrm{~N}$. Note the fine abrasive grooves.

assuming a hydrostatic stress state and using Eq. (4), residual stresses could be calculated. Table II shows the specific strain and stress of the alumina matrix in the micro/nanocomposites. The diffraction elastic constants used are $E_{\mathrm{ZrO}_{2}}=226 \mathrm{GPa}$, $E_{\mathrm{Al}_{2} \mathrm{O}_{3}}=398 \mathrm{GPa}, v_{\mathrm{ZrO}_{2}}=0.25 \mathrm{GPa}$, and $v_{\mathrm{Al}_{2} \mathrm{O}_{3}}=0.231 \mathrm{GPa}$. They were calculated by the program XEC, ${ }^{40}$ using a Kröner model $^{41}$ and taking the single-crystal elastic constants quoted in Gnaupel-Herold et al. ${ }^{42}$ Expectedly, the calculated stress follows the strain closely. In fact, we can calculate the microstress in the zirconia if we know that in the alumina and we apply the rule of mixtures

$$
(1-f) \sigma_{\mathrm{Al}_{2} \mathrm{O}_{3}}+f \sigma_{\mathrm{ZrO}_{2}}=0
$$

where $f$ is the $\mathrm{ZrO}_{2}$ volume fraction. Equation (5) makes use of the reasonable assumption that no macrostress is present. The estimated hydrostatic tensile stress was found to be about $1.2 \pm 0.2 \mathrm{GPa}$.

The matrix peak width for monolithic alumina and micro/ nanocomposite are also shown in Table II. The grain size and the instrumental contribution are the same in the two cases, and so the decrease in the alumina peak with of the micro/nanocomposite could indeed be due to distortion: the presence of $\mathrm{ZrO}_{2}$ nanoparticles situated at the grain boundaries or embedded within the alumina grains could create large gradients.

\section{Discussion}

The $\mathrm{Al}_{2} \mathrm{O}_{3} / \mathrm{ZrO}_{2}$ micro/nanocomposites show a higher strength and fracture toughness $\left(K_{\mathrm{I} C}\right)$ than the monolithic alumina materials. The fact that the mechanical properties of the micro/ 
Table II. Neutron Diffraction Residual Strain, Stress, and Peak Width in the $\mathrm{Al}_{2} \mathrm{O}_{3}$ Matrix of the Micro/Nanocomposites

\begin{tabular}{lccc}
\hline $\mathrm{Al}_{2} \mathrm{O}_{3}$ & $\begin{array}{l}\text { Hydrostatic } \\
\text { strain, } \varepsilon(\mu \varepsilon)\end{array}$ & $\begin{array}{c}\text { Hydrostatic } \\
\text { stress, } \sigma(\mathrm{MPa})\end{array}$ & $\begin{array}{c}\text { Peak } \\
\text { width }\left(^{\circ}\right)\end{array}$ \\
\hline Bulk & - & - & $0.64 \pm 0.01$ \\
Nanocomposite & $-115 \pm 35$ & $-20 \pm 7$ & $0.61 \pm 0.01$ \\
\hline
\end{tabular}

nanocomposite are superior to the monolithic material with a similar grain size supports the idea of the existence of a toughening mechanism acting at a smaller scale than the grain size of the material. Such a mechanism can be connected with the inter- and intragranular location of the $\mathrm{ZrO}_{2}$ nanoparticles. A bridging zone mechanism such as mechanical or frictional interlocking or pullout should be excluded, because the nanocomposites do not show $R$-curve behavior. ${ }^{43}$ Therefore, only an intrinsic mechanism acting ahead of or directly behind the crack tip can be assumed to be applicable for these micro/nanocomposites. On the other hand, the $\mathrm{ZrO}_{2}$ particles are quite below the critical size for phase transformation. ${ }^{44}$ Hence, the only possible mechanism that can contribute to toughness is the generation of residual stresses in the matrix and the particles during cooling from the sintering temperature. This residual stress is due to the differences between the elastic moduli and the linear thermal expansion coefficients between the alumina matrix $\left(\alpha_{\mathrm{Al}_{2} \mathrm{O}_{3}}=8 \times 10^{-6 \circ} \mathrm{C}\right)$ and zirconia nanoparticles $\left(\alpha_{\mathrm{ZrO}_{2}}=12 \times 10^{-6 \circ} \mathrm{C}\right)$. When the nanocomposite is cooled from the sintering temperature, the second-phase nanoparticles, having a higher thermal expansion coefficient than that of the matrix, contract more than the alumina grains. Because no pressure was applied during sintering, the residual stresses in each phase were expected, and indeed were found, to be hydrostatic. As expected, the calculated hydrostatic stress in the $\mathrm{Al}_{2} \mathrm{O}_{3}$ matrix grains is compressive $(\approx 20 \mathrm{MPa})$ and tensile on the $\mathrm{ZrO}_{2}$ nanoparticles $(\approx 1.2 \mathrm{GPa})$. The result showed general agreement with the elastic model and the previous measurements performed by X-ray diffraction. ${ }^{34}$ The stress is locked in the sintered body and significantly influences the microstructural properties, particularly the stress state within alumina grains and the interfacial bonding between them. The compressive stresses around nanoparticles located within the alumina grains can either delay the formation of microcracks or generate crack shielding stress when dispersoids are sufficiently close and placed on the opposite sides of the crack. Additionally, the intergranular nanoparticles situated on the grain boundaries markedly strengthened the nanocomposite compared with the monolithic. The high internal compressive stress acting on the alumina/ alumina interfaces enhances the formation of a strong boundary structure.

\section{(1) Wear Behavior}

The monolithic alumina and nanocomposites exhibit a load-dependent wear transition that is associated with a one to two orders of magnitude increase in specific wear rate. ${ }^{9}$ Pretransition behavior was associated with mild wear, ${ }^{45}$ in which only the roughening of the surface was associated with differential wear between grains. In other words, the wear rate appears to be dependent on the crystallographic orientation. The mechanisms of material removal in the mild wear regime of alumina materials are still poorly understood. Although the surface may become smoother, some fine-scale features are often present, for example, microscale abrasion. It is clear that significant fracture is absent in this regime. Plastic deformation, grooving, and singlegrain pullout are all dominant mechanisms. It is reasonable to consider that the grain boundary cracks occur because of the combined effects of applied stress asperity contacts, residual thermal mismatch stresses, and the elastic strain associated with the dislocation pileup. Wear occurred primarily at asperity tips either as abrasion or microfracture. This generates subsurface intergranular cracking and leads to subsequent grain pullouts.

In the $\mathrm{Al}_{2} \mathrm{O}_{3}-\mathrm{ZrO}_{2}$ micro/nanocomposites, the sliding process can excite surface dislocations and twinning just as in $\mathrm{Al}_{2} \mathrm{O}_{3}$. However, the surface is not the only dislocation source. The mismatches in thermal expansion and Young's modulus between the matrix and the dispersed nanoparticles yield highly localized residual stresses around the nanoparticles. These tensile stresses around intergranular particle boundaries can relax faster, through grain boundary diffusion, than that around intragranular particles where relaxation occurs through lattice diffusion. When an external stress is applied to the surface by the sliding process, all of the dislocation sources below the surface may be activated, rather than just the surface sources as in the monolithic $\mathrm{Al}_{2} \mathrm{O}_{3}$. Such an extensive plastic flow can lead to a more homogeneously distributed residual stresses zone in the nanocomposites that can influence the wear behavior. For stable $\mathrm{ZrO}_{2}$ nanoparticles evenly dispersed within $\mathrm{Al}_{2} \mathrm{O}_{3}$ grains, each nanoparticle can be considered to exert a radial tensile stress on the surrounding matrix. This decays into the matrix as the inverse cube of distance from the nanoparticle, and reach a maximum value at the interface between the matrix and the nanoparticle. However, the maximum value is inversely proportional to the particle size. From the considerations of force equilibrium at this interface, the hydrostatic tensile stress within the $\mathrm{ZrO}_{2}$ nanoparticles $(1.2 \mathrm{GPa})$ must be equal to the maximum radial tensile stress in the $\mathrm{Al}_{2} \mathrm{O}_{3}$ matrix. For a thermal expansion coefficient ratio $\alpha p / \alpha m>1$, the maximum shear stress is slightly smaller than the value of the radial stress. ${ }^{46}$ Taking into account that the maximum shear stress plays a major role as a driving force to create dislocations in the matrix, the magnitude of this stress on the nanoparticle/matrix grain boundary is great enough to induce dislocations around the particle. The generation of dislocations around dispersed intragranular nanoparticles is a common observation in other ceramic nanocomposites. ${ }^{10,30,47,48}$

An alternative explanation for the lower wear rate of the micro/nanocomposites is the modification of grain boundary strength by the addition of nanoparticles of $\mathrm{ZrO}_{2}$ to $\mathrm{Al}_{2} \mathrm{O}_{3}$. Normally, in alumina, grain boundaries act as weak points for crack initiation. The local residual tensile microstresses developed in alumina as a result of thermal anisotropy were shown to be about $100 \mathrm{MPa}^{49}$ In the case of intergranular $\mathrm{ZrO}_{2}$ nanoparticles located at the grain boundaries, the compressive tangential component of the residual stress influences the $\mathrm{Al}_{2} \mathrm{O}_{3}$ / $\mathrm{Al}_{2} \mathrm{O}_{3}$ matrix grain boundary strength positively. These residual stresses reduce the instability range of microcrack precursors at grain junctions and increase the initial level of driving force for critical microcrack extension. This can account for the decrease of grain pullout observed in the micro/nanocomposites samples. Therefore, the grain boundaries in micro/nanocomposites are reinforced, inhibiting intergranular crack propagation and preventing the nucleation of grain boundary cracks due to a reduction in the anisotropy of the thermal residual stress.

Todd et al $^{50}$ found that the addition of $5 \mathrm{wt} \% \mathrm{SiC}$ nanoparticles to alumina reduced the intergrain stresses resulting from thermal expansion anisotropy between two adjacent grains by about $7 \%$. They indeed used neutron diffraction measurements of strain normal to the (006) and (300) planes. As mentioned before, if a material is subjected to an inhomogeneous strain field, the diffraction peak profile will also be broadened. In our measurements, a decrease of the $\mathrm{Al}_{2} \mathrm{O}_{3}$ peak width by going from the monolithic to the micro/nanocomposite matrix has been found (Table II). The peak width decrease of the micro/nanocomposite shows that the stress state in the alumina matrix of the micro/nanocomposite is more homogeneous. This reduction in the intergrain stresses may influence the crack initiation and propagation in the micro/nanocomposites and therefore the wear behavior.

Let us now consider a crack along a grain boundary in monolithic alumina under the action of surface sliding. There are two contributions to the stress intensity at the crack tip: one caused 
by the sliding and the other by the intergrain stresses. The sliding contribution may result from the direct force of the abrading particles or from plastic deformation caused by them. This stress intensity diminishes in the nanocomposites because of the more homogeneous residual stresses distribution, due to extensive plastic flow produced by the dislocation activity. Additionally, the stress intensity caused by the tensile intergrain stresses can be reduced in the nanocomposites by the presence of internal compressive stress acting on the alumina/alumina interfaces, produced by the $\mathrm{ZrO}_{2}$ nanoparticles at grain boundaries. In the monolithic alumina, if the grain size is large, or at an abnormally large grain, as our case, the tensile intergrain stress is high and fracture may originate at microcracks. In contrast, in the nanocomposites, the intergrain stresses are reduced and so that the crack starts to grow later. This mechanism is relevant at lower loads because at higher loads, the high applied stress intensity factor is not compensated by the opposite stress intensity factor due to the compressive residual stress generated by the zirconia nanoparticles. In severe wear, the nominal contact pressure produces a stress intensity that exceeds $K_{\mathrm{I} C}$ and causes microscopic fracture such as tensile cracks. At the sharp edges of the cracks, the stress intensity is high and wear occurs, producing many wear particles. These particles formed third bodies in the contact and caused more localized fracture and grain pullouts, resulting in larger wear particles being produced. These large wear particles then serve to intensify the stress at contact. Therefore, the high wear rate sets on.

The results shown and the ideas set forth in the above discussion demonstrate the feasibility of the micro/nanocomposite concept in terms of wear resistance ceramic microstructural design. Many applications require not only high wear resistance but also high toughness and high strength. In terms of microstructural design, the requirements for wear resistance are often different or even contradictory to those for high fracture toughness. For example, fine equiaxed grained alumina with a strong grain boundary improves wear resistance, but decreases toughness. Conversely, large-grained alumina with weak grain boundaries improves toughness, but yields low wear resistance. Some researchers suggested that a compromise must be made between these requirements. ${ }^{51,52}$ One can sacrifice wear resistance to gain toughness or one can improve the wear resistance at the expense of toughness. However, this does not have to be the case. The design of a micro/nanocomposite with inter/intrananoparticles provides the possibility to tailor new materials with toughening mechanisms operating on a scale smaller than that of the matrix microstructure. This enhances the "intrinsic" fracture properties of the material. This intrinsic increase of resistance to crack initiation and propagation due to a structural synergism between the matrix phase and dispersoid should lead to an increase in the catastrophic failure strength and wear resistance. In other words, strength, toughness, and wear resistance increases are compatible in this case.

In summary, improvements in "intrinsic" mechanical properties and the wear resistance in the mild regime of micro/nanocomposite composites make them promising candidates for biomedical applications, for example, total joint (hip and knee) replacement, applications where very small cracks are expected.

\section{Conclusions}

On the bases of the reported results and their implications, the following conclusions can be drawn:

(1) An $\mathrm{Al}_{2} \mathrm{O}_{3} / \mathrm{ZrO}_{2}$ micro/nanocomposite has two main toughening mechanisms: (1) formation of a compressive residual stress field within the matrix grain (around the intragranular nanoparticles) because of the large thermal expansion mismatch with the $\mathrm{ZrO}_{2}$ particles. These stresses may slow down the rate of crack advancement or delay their formation. (2) Creation of local compressive stresses on adjacent $\mathrm{Al}_{2} \mathrm{O}_{3} / \mathrm{Al}_{2} \mathrm{O}_{3}$ grain boundaries due to the presence of intergranular nanoparticles, thus strengthening boundaries, providing a high resistance to crack initiation.

(2) In the monolithic alumina, a large grain size, combined with the inherently strong anisotropy in thermal expansion, creates tensile stresses at the grain boundaries within the ceramic that increases the tendency to brittle, intergranular fracture under conditions of abrasive wear. Therefore, plastic deformation plays only a minimal role in this material response to the wear environment, and the wear rate is high.

(3) For a similar alumina grain size, the addition of $\mathrm{ZrO}_{2}$ nanoparticles to alumina to form an inter/intragranular composite results in a substantial reduction in the sliding wear rate of over an order of magnitude in the mild wear regime at $20 \mathrm{~N}$.

(4) The lower wear rate during the pretransition period for the nanocomposites than for the monolithic alumina implies that the nominal contact producing stress intensity is insufficient to cause macroscopic fracture. The effect of intergranular nanoparticles is to produce an additional compressive stress component generated on the $\mathrm{Al}_{2} \mathrm{O}_{3} / \mathrm{Al}_{2} \mathrm{O}_{3}$ grain boundary, which overlaps with the local residual tensile stresses between two adjacent alumina grains due to the matrix thermal expansion anisotropy. This may reduce the wear rate in the nanocomposites compared with the monolithic alumina under the present test conditions. From strain measurements by neutron diffraction, we can conclude that the addition of nanoparticles reduces the intergrain stresses and can also explain the strength increase. Moreover, the more homogeneous deformation mechanism in the nanocomposite at low loads $(20 \mathrm{~N})$ with respect to the unreinforced alumina, due to plastic flow induced by the dislocation generation around the intragranular nanoparticles, may contribute to the observed suppression of near-surface fracture.

(5) The micro/nanocomposite with inter/intragranular $\mathrm{ZrO}_{2}$ nanoparticles provides the possibility to design new materials with toughening mechanisms operating on a scale smaller than that of the matrix microstructure. This enhances the "intrinsic" fracture properties of these materials and their wear resistance in the mild regime. Moreover, it makes them promising candidates for bearing applications and well-polished surface finish, for example for total joint replacements.

\section{References}

${ }^{1}$ B. Kerkwijk, L. Winnubst, E. J. Mulder, and H. Verweij, "Processing of Homogeneous Zirconia-Toughened Alumina Ceramics With High Dry-Sliding Wear Resistance,", J. Am. Ceram. Soc., 82 [8] 2087-93 (1999).

${ }^{2}$ Y. J. He, A. J. A. Winnubst, D. J. Schipper, A. J. Burggraaf, and H. Verweij, "Effects of a Second Phase on the Tribological Properties of $\mathrm{Al}_{2} \mathrm{O}_{3}$ and $\mathrm{ZrO}_{2} \mathrm{Ce}$ ramics," Wear, 210, 178-87 (1997).

${ }^{3}$ K. Cherif, B. Gueroult, and M. Rigaud, "Wear Behaviour of Alumina Toughened Zirconia Materials,” Wear, 199, 113-21 (1996).

${ }^{4}$ Y. S. Wang, C. He, B. J. Hockey, P. I. Lacey, and S. M. Hsu, "Wear Transitions in Monolithic Alumina and Zirconia-Alumina Composites," Wear, 156, 181-3 (1995).

${ }^{5}$ V. Sergo, V. Lughi, G. Pezzotti, E. Lucchini, S. Meriani, N. Muraki, G. Katagiri, S.Lo Casto, and T. Nishida, "The Effect of Wear on the Tetragonal-to-Monoclinic Transformation and the Residual Stress Distribution in Zirconia-Toughened Alumina Cutting Tools," Wear, 214, 264-70 (1998).

${ }^{6}$ S.-J. Cho, H. Moon, B. J. Hockey, and S. M. Hsu, "The Transition from Mild to Severe Wear in Alumina During Sliding," Acta Metall., 40 [1] 185-92 (1992).

${ }^{7}$ H. Liu and M. E. Fine, "Modelling of Grain-Size-Dependent MicrofractureControlled Sliding Wear in Polycrystalline Alumina," J. Am. Ceram. Soc., 76 [9] 2393-6 (1993).

${ }^{8}$ C. He, Y. S. Wang, and S. M. Hsu, "Effect of Microstructure on the Wear Transition of Zirconia-Toughened Alumina," Wear, 162-164, 314-21 (1993).

${ }^{9}$ J. D. O. Barceinas-Sanchez and W. M. Rainforth, "On the Role of Plastic Deformation During the Mild Wear of Alumina," Acta Mater., 46 [18] 6475-83 (1998).

${ }^{10} \mathrm{H}$. Wu, B. J. Inkson, and S. G. Roberts, "Subsurface Deformation of Machined $\mathrm{Al}_{2} \mathrm{O}_{3}$ and $\mathrm{Al}_{2} \mathrm{O}_{3} / 5 \mathrm{vol} \% \mathrm{SiC}$ Nanocomposite," J. Microsc., 201 [2] 212-20 (2001).

${ }^{11}$ B. J. Inkson, "Dislocations and Twinning Activated by the Abrasion of $\mathrm{Al}_{2} \mathrm{O}_{3}, "$ Acta Mater., 48, 1883-5 (2000).

${ }_{12}$ J. F. Bartolomé, C. Pecharromán, J. S. Moya, A. Martín, J. Y. Pastor, and J. Llorca, "Percolative Mechanism of Sliding Wear in Alumina/Zirconia Composites," J. Eur. Ceram. Soc., 26, 2619-25 (2006).

${ }^{13}$ J. A. Tichy and D. M. Meyer, "Review of Solid Mechanics in Tribology," Int. J. Solid Struct., 37, 391-400 (2000). 
${ }^{14}$ B. Kerkwijk, E. Mulder, and H. Verweij, "Zirconia-Alumina Ceramic Composites With Extremely High Wear Resistance," Adv. Eng. Mater., 1 [1] 69-71 (1999).

${ }^{15}$ H. Mills and S. Blackburn, "Zirconia Toughened Aluminas by Hydro-Thermal Processing," J. Eur. Ceram. Soc., 20, 1085-90 (2000).

${ }^{16}$ Y. Matsumoto, K. Hirota, O. Yamaguchi, S. Inamura, H. Miyamoto, N. Shiokawa, and K. Tsuji, "Mechanical Properties of Hot Isostatically Pressed Zirconia-Toughened Alumina Ceramics Prepared from Coprecipitated Powders," J. Am. Ceram. Soc., 76 [10] 2677-80 (1993).

${ }^{17}$ G. J. Liu, H. B. Qiu, R. Todd, R. J. Brook, and J. K. Guo, "Processing and Mechanical Behavior of $\mathrm{Al}_{2} \mathrm{O}_{3} / \mathrm{ZrO}_{2}$ Nanocomposites," Mater. Res. Bull., 33 [2] 281-8 (1998).

${ }^{18}$ M. Schehl, L. A. Díaz, and R. Torrecillas, "Alumina Nanocomposites from Powder-Alkoxide Mixtures," Acta Mater., 50, 1125-39 (2002).

${ }^{19}$ Y. Nishikawa, H. Kume, S. Inamura, H. Miyamoto, and S. Díaz de la Torre, "Evaluation of $\mathrm{ZrO}_{2}$-Dispersed $\mathrm{Al}_{2} \mathrm{O}_{3}$ Ceramics Prepared by Coprecipitation Technique," J. Ceram. Soc. Jpn., 112 [5] s350-3 (2004).

${ }^{20}$ A. H. De Aza, J. Chevalier, G. Fantozzi, M. Schehl, and R. Torrecillas, "Slow-Crack-Growth Behavior of Zirconia-Toughened Alumina Ceramics Processed by Different Methods," J. Am. Ceram. Soc., 86 [1] 115-20 (2003).

${ }^{21}$ N. B. Thomsen and B. L. Karihaloo, "Optimum Microstructure of Transformation-Toughened Ceramics for Enhanced Wear Performance," J. Am. Ceram. Soc., 78 [1] 3-8 (1995).

${ }^{22}$ S. Deville, J. Chevalier, Ch. Dauvergne, G. Fantozzi, J. F. Bartolomé, J. S. Moya, and R. Torrecillas, "Microstructural Investigation of the Aging Behavior of Yttria-Stabilised Zirconia Toughened Alumina Composites," J. Am. Ceram. Soc., 88 [5] 1273-80 (2005).

${ }^{23}$ S. Deville, J. Chevalier, G. Fantozzi, J. F. Bartolomé, J. Requena, J. S. Moya, L. A. Díaz, and R. Torrecillas, "Low-Temperature Ageing of Zirconia-Toughened Alumina Ceramics and Its Implication in Biomaterial Implants," J. Eur. Ceram. Soc., 23, 2975-82 (2003).

${ }^{24}$ K. Niihara, "New Design Concept of Structural Ceramics. Ceramic Nanocomposites," J. Ceram. Soc. Jpn., 99 [10] 974-82 (1991).

${ }^{25}$ M. Sternitzke, "Review: Structural Ceramic Nanocomposites," J. Eur. Ceram. Soc., 17, 1061-82 (1997).

${ }^{26}$ S. Kovalev, T. Ohji, Y. Yamauchi, and M. Sakai, "Grain Boundary Strength in Non-Cubic Ceramic Polycrystals With Misfitting Intragranular Inclusions (Nanocomposites)," J. Mater. Sci., 35, 1405-12 (2000).

${ }^{27}$ R. W. Davidge, P. C. Twigg, and F. L. Riley, "Effects of Silicon Carbide Nano-Phase on the Wet Erosive Wear Polycrystalline Alumina," J. Eur. Ceram. Soc., 16, 799-802 (1996).

${ }^{28}$ H. Kara and S. G. Roberts, "Polishing Behavior and Surface Quality of Alumina and Alumina/Silicon Carbide Nanocomposites," J. Am. Ceram. Soc., 83 [5] 1219-25 (2000).

${ }^{29}$ M. Sternitzke, E. Dupas, P. Twigg, and B. Derby, "Surface Mechanical Properties of Alumina Matrix Nanocomposites," Acta Mater., 45, 3963-73 (1997).

${ }^{30} \mathrm{H}$. Wu, S. G. Roberts, and B. Derby, "Residual Stress and Subsurface Damage in Machined Alumina and Alumina/Silicon Carbide Nanocomposites Ceramics," Acta Mater., 49, 507-17 (2001).

${ }^{31}$ J. Rodriguez, A. Martin, J. Y. Pastor, J. Llorca, J. F. Bartolome, and J. S. Moya, "Sliding Wear of Alumina/Silicon Carbide Nanocomposites," J. Am. Ceram. Soc., 82 [8] 2252-4 (1999).

${ }^{32}$ H. J. Chen, W. M. Rainforth, and W. E. Lee, "The Wear Behaviour of $\mathrm{Al}_{2} \mathrm{O}_{3}$ SiC Ceramic Nanocomposites," Scr. Mater., 42, 555-60 (2000).
${ }^{33}$ W. M. Rainforth, "The Wear Behaviour of Oxide Ceramics-A Review," J. Mater. Sci., 39, 6705-21 (2004).

${ }^{34}$ J. Chevalier, S. Deville, G. Fantozzi, J. F. Bartolomé, C. Pecharroman, J. S Moya, and R. Torrecillas, "Nano-Structured Ceramic Oxides With a Slow Crack Growth Resistance Close to Covalent Materials," Nano Lett., 5 [7] 1297-301 (2005)

${ }^{35}$ P. Miranzo and J. S. Moya, "Elastic/Plastic Indentation in Ceramics: A Fracture Toughness Determination Method," Ceram. Int., 10, 147-52 (1984).

${ }^{36}$ D. J. Hughes, G. Bruno, T. Pirling, and P. J. Withers, "First Impressions of SALSA: The New Engineering Instrument at ILL," Neutron News, 17, 28-32 (2006)

${ }^{37}$ T. Pirling, G. Bruno, and P. J. Withers, "SALSA-A New Instrument for Strain Imaging in Engineering Materials and Components," Mater. Sci. Eng. A, 437, 139-44 (2006)

${ }^{38} \mathrm{P}$. J. Webster, "Role of Neutron Diffraction in Engineering Stress Analysis"; pp. 21-36 in NATO Series, Vol. 216, Measurement of Residual and Applied Stress Using Neutron Diffraction, Edited by M. J. Hutchings, and A. D. Krawitz. Kluwer Academic Publishers, the Netherlands, 1992.

${ }^{39}$ D. Richard, "The LAMP Project"; LAMP, the Large Array Manipulation Program. http://www.ill.fr/data_treat/lamp/front.html. ILL, 2006.

${ }^{40} \mathrm{H}$. Wern, R. Johannes, and H. Walz, "Dependence of X-Ray Elastic Constants on Diffraction Plane," Physica Status Solidi (B), 206, 545-57 (1998).

${ }^{41}$ E. Kröner, "Berechnung der elastischen Konstanten des Vielkristalls aus den Konstanten des Einkristalls," Z. Phys., 151 [4] 504-18 (1958).

${ }^{42}$ T. Gnaupel-Herold, P. C. Brand, and H. J. Prask, "Calculation of SingleCrystal Elastic Constants for Cubic Crystal Symmetry from Powder Diffraction Data," J. Appl. Crystallogr., 31 [Part 6] 929-35 (1998).

${ }^{43}$ J. F. Bartolomé, "Short-Crack Growth Behaviour of Alumina-Zirconia Micro and Nanocomposites for Biomechanical Components," Biomaterials, submitted.

${ }^{44}$ A. H. Heuer, N. Claussen, W. M. Kriven, and M. Rühle, "Stability of Tetragonal $\mathrm{ZrO}_{2}$ Particles in Ceramic Matrices," J. Am. Ceram. Soc., 65 [12] 642-50 (1982).

${ }^{45}$ K. Adachi and K. Kato, "Formation of Smooth Wear Surfaces on Alumina Ceramics by Embedding and Tribo-Sintering of Fine Wear Particles," Wear, 245 [1-2] 84-95 (2000)

${ }^{46}$ H. Awaji, S.-M. Choi, and E. Yagi, "Mechanisms of Toughening and Strengthening in Ceramic-Based Nanocomposites," Mech. Mater., 34, 411-22 (2002)

${ }^{47}$ S.-M. Choi and H. Awaji, "Nanocomposites-A New Material Design Concept," Sci. Technol. Adv. Mater., 6, 2-10 (2005).

${ }^{48}$ N. Bamba, Y. H. Choa, T. Sekino, and K. Niihara, "Mechanical Properties and Microstructure for $3 \mathrm{~mol} \%$ Yttria Doped Zirconia/Silicon Carbide Nanocomposites," J. Eur. Ceram., 23, 773-80 (2003).

${ }^{49}$ J. E. Blendell and R. L. Coble, "Measurement of Stress Due to Thermal-Expansion Anisotropy in $\mathrm{Al}_{2} \mathrm{O}_{3}$," J. Am. Ceram. Soc., 65 [3] 174-8 (1982).

${ }^{50}$ R. I. Todd, M. A. M. Bourke, C. E. Borsa, and R. J. Brook, "Neutron Diffraction Measurements of Residual Stresses in Alumina/SiC Nanocomposites," Acta Mater., 45 [4] 1791-800 (1997).

${ }^{51}$ S.-J. Cho, B. J. Hockey, B. Lawn, and S. Bennison, "Grain-Size and R-Curve Effects in the Abrasive Wear of Alumina," J. Am. Ceram. Soc., 72 [7] 1249-52 (1989).

${ }^{52}$ B. A. Latella and B. H. Connor, "Effect of Post-Sintering Heat-Treatments on the Erosive Wear Behaviour of Liquid-Phase-Sintered Aluminas," J. Mater. Sci., 35, 3505-17 (2000). 